\title{
Estudo da adição de argila expandida e EPS como agregados na elaboração de concreto leve
}

\author{
Study of the addition of expanded clay and EPS as aggregates in the elaboration of light concrete
}

\author{
Julio E. C. M. Moncada ${ }^{\dagger *}$, Leonardo D. S. Flor ${ }^{\dagger}$, Viviane A. Silva ${ }^{\dagger}$, Jonas S. Pacheco ${ }^{\dagger}$
}

Como citar esse artigo. Moncada, JECM; Flor, LDS; Silva, VA; Pacheco, JS. Estudo da adição de argila expandida e EPS como agregados na elaboração de concreto leve. Revista Teccen. 2019 Jan/Jun; 12 (1): 02-07.

\begin{abstract}
Resumo
O presente trabalho apresenta uma análise comparativa entre o concreto convencional e o concreto leve com a substituição do agregado graúdo pela argila expandida e poliestireno expandido. Observa-se que o emprego destes elementos em materiais cimentícios viabiliza a redução do peso próprio de estruturas em concreto, assegurando uma minoração econômica no custo total da obra onde for aplicado o concreto leve. Para a realização deste estudo o fator água aglomerante atribuído ao concreto leve foi superior em relação ao traço elaborado para concreto convencional por possuir um agregado poroso. O projeto experimental realizou-se em laboratório em temperatura de $24,5^{\circ} \mathrm{C}$ e umidade relativa do ar de $71 \% \mathrm{Rh}$, obedecendo às normas regulamentadoras. $\mathrm{O}$ fator de eficiência obtido no concreto leve foi superior em todos os ensaios realizados, no entanto sua resistência mecânica à compressão apresentou um resultado inferior ao concreto convencional, porém ambos os concretos possuem função estrutural que estabelece como um valor mínimo a resistência de $20 \mathrm{MPa}$ de acordo com a NBR 6118:2014. Contudo, observou-se que a adição de argila expandida e poliestireno expandido é viável, pois reduz a massa específica do concreto o que gera um alívio de carregamento nas estruturas reduzindo o custo global da construção. A segurança estrutural mantém-se garantida pelo fator eficiência.
\end{abstract}

Palavras-Chave: concreto, agregado, eficiência.

\begin{abstract}
The present work presents a comparative analysis between the conventional concrete and the light concrete with the replacement of the large aggregate by the expanded clay and expanded polystyrene. It is observed that the use of these elements in cementitious materials allows the reduction of the weight of concrete structures, ensuring an economic reduction in the total cost of the work where light concrete is applied. For the accomplishment of this study, the binder water factor attributed to light concrete was superior in relation to the trait elaborated for conventional concrete because it possesses a porous aggregate. The experimental project was performed in a laboratory at a temperature of $24.5{ }^{\circ} \mathrm{C}$ and relative humidity of $71 \% \mathrm{Rh}$, obeying regulatory standards. The efficiency factor obtained in the light concrete was superior in all the tests carried out, however its mechanical strength to the compression presented an inferior result to the conventional concrete, but both concretes have a structural function that establishes as a minimum the resistance of $20 \mathrm{MPa}$ according to NBR 6118: 2014. However, it has been observed that the addition of expanded clay and expanded polystyrene is feasible, because it reduces the specific mass of the concrete which generates a load relief in the structures reducing the overall cost of the construction. Structural safety is guaranteed by the efficiency factor.
\end{abstract}

Keywords: concrete, aggregate, efficiency.

\section{Introdução}

Por apresentar baixos valores quanto à massa específica, o uso do concreto leve reduz significativamente o peso próprio dos elementos cimentícios, influenciando diretamente na economia na estrutura de fundação (HER-YUNG, 2009). No Brasil, por ser uma tecnologia pouco explorada, utilizase apenas o concreto convencional. Porém, a procura por matérias singulares que possuam uma baixa massa específica e características que atendam as normas regulamentadoras é um enorme desafio.

Segundo Pedroso (2009), o concreto é o segundo material mais utilizado no mundo. No qual agrega um enorme valor na construção civil, fazendo com que sua importância para o crescimento econômico seja crucial. Entretanto, avaliando o uso do concreto convencional que possui uma elevada massa específica tornando-o menos eficiente, utilizou-se neste concreto como agregado graúdo a argila expandida e poliestireno expandido com o intuito de diminuir a massa específica.

\footnotetext{
Afiliação dos autores:

† Universidade de Vassouras - UV, Vassouras - RJ, Brasil
}

* Email para correspondência: julio.costamaldonado@gmail.com 


\section{Concreto Leve}

Visando tal necessidade, de encontrar materiais que proporcionem benefícios, este presente artigo mostra uma avalição de um concreto leve que possui uma mescla de argila expandida e EPS como agregados graúdos. Segundo Spitzner (1994) e Holm (2000), o concreto leve de alto desempenho pode ser determinado por um parâmetro que relaciona resistência à compressão e massa específica.

\section{Características da Argila expandida}

A argila expandida é um agregado obtido através do aquecimento de diferentes tipos de argila à uma temperatura estimada em $1200{ }^{\circ} \mathrm{C}$, exposta a tal temperatura este agregado emite gases expandindo-a em até sete vezes seu volume inicial. Esses mesmos gases não são emitidos ao exterior sendo retido na argila após o resfriamento, assim diminuindo a massa unitária do material, sendo utilizada em concreto leve, possuindo uma densidade aparente de $500 \mathrm{Kg} / \mathrm{m}^{3} \pm 10 \%$ utilizouse como principal agregado graúdo visando abaixar o preso próprio de estruturas, tendo como compostos os elementos químicos demonstrados na figura 01 .

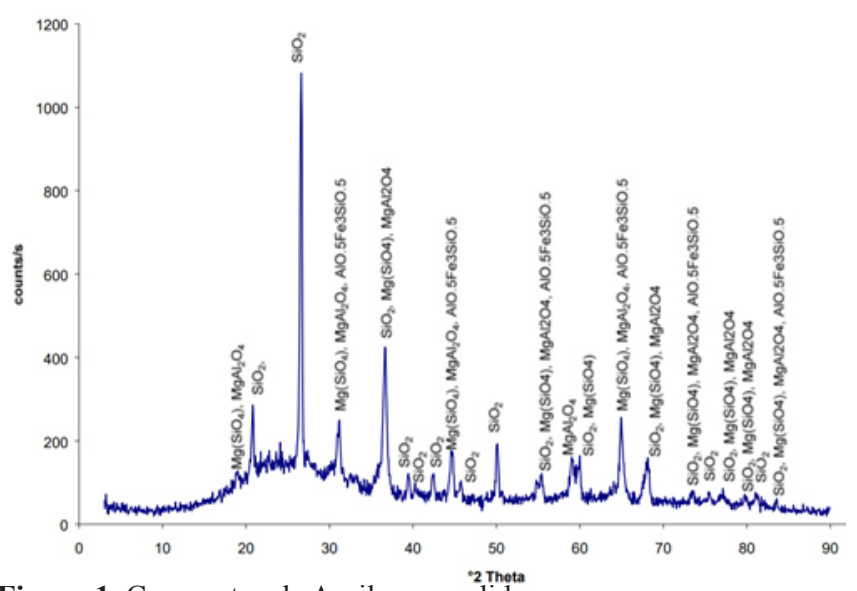

Figura 1. Compostos da Argila expandida.

Fonte: Moravia et al., 2014.

As principais vantagens como agregado são:

- Baixa densidade: Quando comparado a agregados comuns como brita podendo ser até 2,5 vezes menores.

- Inércia Química: Por ser um material isento de substâncias que possam ter efeitos adversos no cimento e armaduras de aço.

Entretanto, por ser um material que possui seu interior poroso torna-se um agregado que apresenta alta absorção de água.

\section{Característica do EPS}

EPS (Poliestireno expandido) mais conhecido no Brasil, como isopor, descoberto na Alemanha em 1949 no laboratório da BASF. O EPS e composto por $2 \%$ de poliestireno e $98 \%$ de ar. Sendo um plástico celular rígido formado da polimerização do estireno em água. Por ter um baixo custo e características físicas e químicas, apresentou uma posição estável na construção civil. Sendo utilizado por diversos fatores tais como, de isolação térmica, resistência e leveza.

\section{Fator Água/Aglomerante}

A qualidade do concreto está diretamente relacionada com o fator (água/cimento), quanto menor for o valor desta relação, maior será a resistência do concreto, diminuindo também sua permeabilidade e aumentando sua durabilidade. Por sua vez o excesso de água é prejudicial, pois após a evaporação da mesma formam-se espaços vazios. Contudo, por a argila expandida se tratar de um agregado que possui seu interior poroso e uma absorção de água mais elevada que a brita, utilizou-se um fator água/cimento mais elevado.

\section{Projeto Experimental}

\section{Traço dos concretos dos corpos-de-prova}

$\mathrm{O}$ intuito do projeto experimental elaborouse dois traços com agregados graúdos distintos nas mesmas proporções de acordo com a tabela 01 indicada. Tal experimento utilizou a tabela de traços elaborados de Caldas-Branco (1974), que demonstra a proporção de 1:1:2 com a relação dos elementos que estima o fck de $40 \mathrm{Mpa}$.

Com o objetivo de analisar a influência da argila expandia e EPS no concreto, o programa experimental concebeu-se na elaboração de corpos de prova a análise de resistência mecânica, a fim de expor seu fator de eficiência.

\section{Slump- Test}

Mais conhecido como Slump-Test, o ensaio de abatimento possui a finalidade de verificar a trabalhabilidade do concreto em seu estado plástico, com o intuito de averiguar se está adequado ao uso a que se designa. Para a realização deste ensaio coletouse uma amostra do concreto, preenchendo uma forma tronco-cônica sobre uma placa de metal nivelada, após o preenchimento da primeira camada aplicou-se 25 golpes com uma haste metálica atingindo a parte inferior da forma, em seguida aplicou-se mais duas camadas golpeando-as 25 vezes cada uma. Posteriormente foi feita a retirada da forma sendo colocada ao lado da massa de concreto podendo assim medir a consistência da massa, como mostra a figura 02 . 


\section{Massa Específica}

A massa específica é obtida através da fórmula I (Eq. 01) de acordo com a NBR 9833:2008.

Massa Específica:

$$
\text { Eq. 01: Pap }=\frac{m_{c o n}-m_{r e c}}{V} \times 1000
$$

Onde:

Pap: Massa específica aparente do concreto. $\left(\frac{\mathrm{kg}}{\mathrm{m}^{3}}\right)$

$m_{\text {con }}$ : Massa do concreto + recipiente $(g) 3$

$m_{\text {rec }}:$ Massa do recipiente vazio $(g)$

$V$ :Volume do recipiente $(l)$

\section{Corpos de prova para ensaio de resistência mecânica à compressão}

A metodologia para a cura e a realização do ensaio de compressão axial foi ministrada em conformidade com a NBR 5738:2015. Onde confeccionou-se 24 corpos de prova cilíndricos com dimensões de 10 $\mathrm{cm}$ de diâmetro por 20 de altura de acordo com NBR 5739:2018 item 4.1.1.1, sendo 3 corpos de prova para cada traço elaborado conforme a tabela 01. O adensamento foi manual (figura 03), respeitando o item 7.4.1.1 obedecendo o número de camadas e golpes, como demonstra a figura2. Em seguida, os corpos de prova foram colocados em um ambiente a uma temperatura de $24,5^{\circ} \mathrm{C}$ e $71 \% \mathrm{Rh}$, sem nenhuma interferência externa. As formas foram retiradas com 7, 14, 21 e 28 dias.

\section{Ensaio de resistência mecânica à compressão}

Para o ensaio de resistência mecânica à compressão, os corpos de prova obedeceram aos itens alvitrados na NBR 5739:2018. "O corpo-de-prova cilíndrico deve ser posicionado de modo que, quando estiver centrado, que a resultante das forças passe pelo centro" (NBR 5739: 2018). Tal ensaio foi realizado com um carregamento constante de $0,45 \mathrm{Mpa} / \mathrm{s}$ durante todo o ensaio como mostra a figura 04 e figura 05 .

\section{Fator de Eficiência}

O Fator de eficiência do material é obtido através da seguinte fórmula (Eq.02):

$$
\text { Eq. 02: } \quad F e=\frac{f c}{\gamma}\left(M p a \cdot \frac{d m^{3}}{K g}\right)
$$

Onde:

$$
\begin{aligned}
& F c=\text { resistência à compressão }(M p a) \\
& \gamma=\text { massa específica do concreto }\left(\frac{\mathrm{kg}}{\mathrm{dm}^{3}}\right)
\end{aligned}
$$

\begin{tabular}{|c|c|c|c|c|c|c|c|}
\hline Traço & $\begin{array}{c}\text { Cimento } \\
\left(\mathbf{m}^{3}\right)\end{array}$ & $\begin{array}{l}\text { Areia } \\
\left(\mathrm{m}^{3}\right)\end{array}$ & $\begin{array}{l}\text { Água } \\
\text { (1) }\end{array}$ & $\begin{array}{l}\text { Brita } \\
\left(\mathrm{m}^{3}\right)\end{array}$ & $\begin{array}{l}\text { Eps } \\
\left(m^{3}\right)\end{array}$ & $\begin{array}{l}\text { Argila expandida } \\
\qquad\left(\mathrm{m}^{3}\right)\end{array}$ & $\begin{array}{l}\text { Fator água/ } \\
\text { aglomerante }\end{array}$ \\
\hline 1 & 0,0074 & 0,0074 & 3,70 & 0,0148 & 0 & 0 & 0,5 \\
\hline 2 & 0,0074 & 0,0074 & 4,40 & 0 & 0,0037 & 0,0148 & 0,6 \\
\hline
\end{tabular}

Tabela 1. Traço elaborados para corpos- de- prova.

Fonte: Os autores.

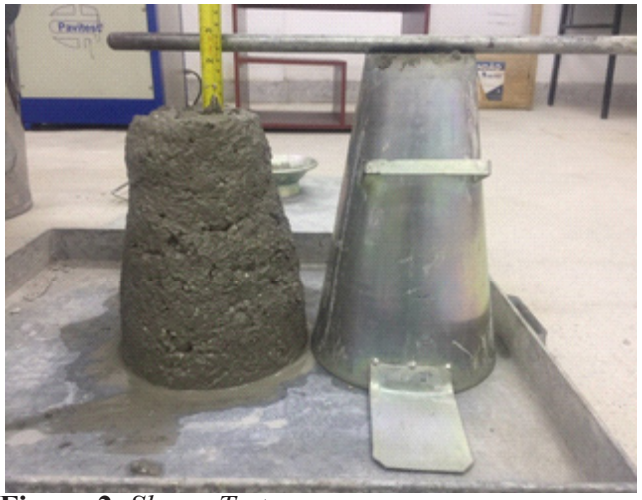

Figura 2. Slump-Test.

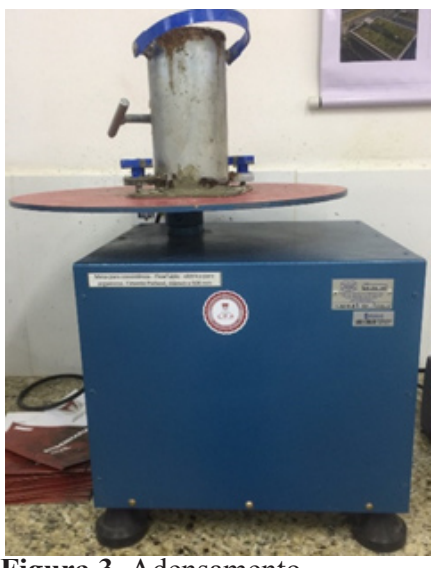

Figura 3. Adensamento. 


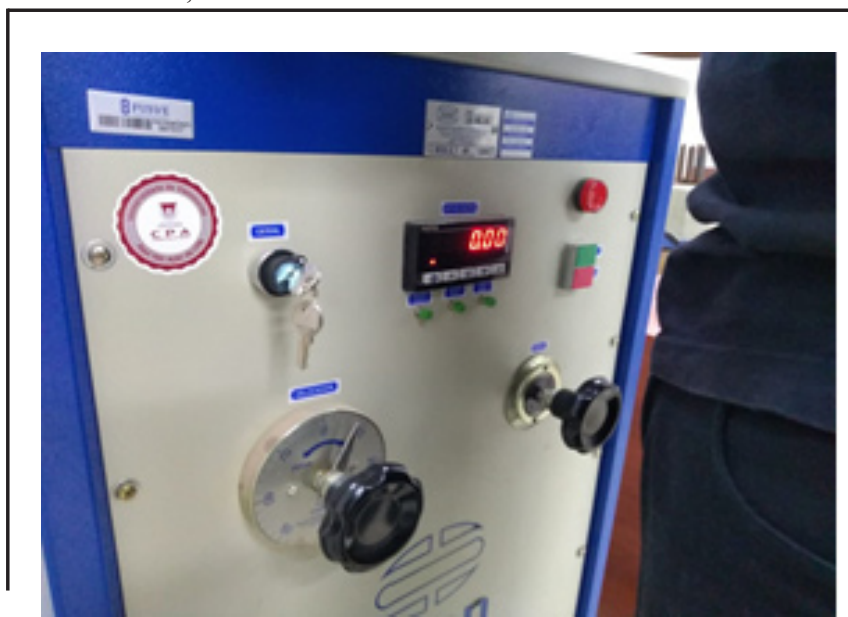

Figura 4. Calibração.

Fonte: Os autores.

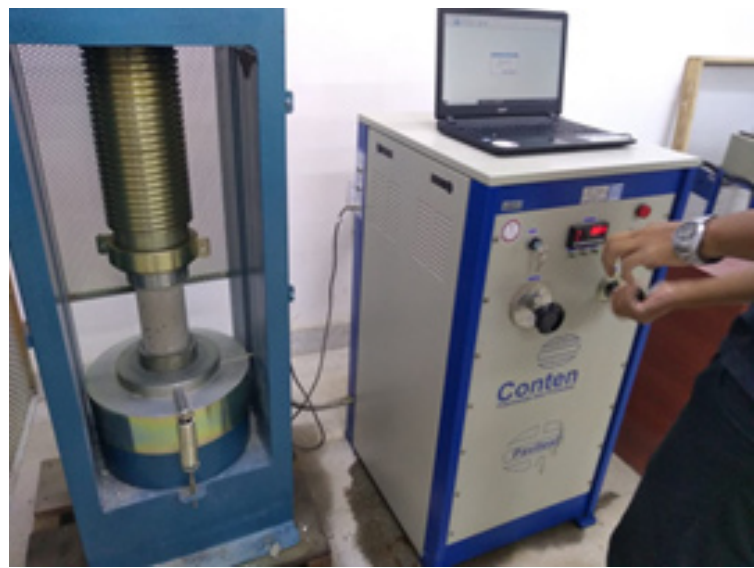

Figura 5. Ensaio de compressão.

Fonte: Os autores.

\section{Resultados}

De acordo com os seguintes cálculos e ensaios realizados, tornou-se possível realizar uma avaliação das características do concreto leve constituído com argila expandida e pérolas e EPS, podendo assim realizar um comparativo com o concreto convencional.

Através da fórmula de massa específica obtiveramse os seguintes resultados como mostra o gráfico 01 .

A trabalhabilidade do concreto dada através do Slump Test obteve-se resultados esperados, sendo $7,4 \mathrm{~cm}$ para o concreto convencional e $6,0 \mathrm{~cm}$ para o concreto leve.

Os corpos de prova realizados submetidos a ensaio de compressão axial apresentaram os seguintes resultados, apresentado no gráfico 2 .

$\mathrm{O}$ fator de eficiência calculado através da fórmula II, onde divide-se a resistência a compressão pela massa específica neste caso com o concreto fresco. De acordo com o gráfico 03 .

\section{Discussões}

O concreto convencional apresentou uma elevada resistência inicial à compressão em relação ao concreto leve, em contrapartida, por possuir em sua composição agregados contendo uma massa específica mais elevada, o concreto convencional apresenta um fator de eficiência inferior ao concreto leve, pois ele possui uma elevada massa específica.

A atenuação da massa específica é indispensável para caracterizar que o concreto com agregado graúdo substituído pela argila expandida e EPS seja um material possível para a utilização em construções. Pode-se dizer que, além disso, a baixa massa específica reduz as solicitações por peso próprio e facilita a produção.

A restringência do valor da massa específica no concreto leve composto por argila expandida e EPS é a principal característica para que ele possa ser um material viável a ser utilizado em construções. Além de minimizar as solicitações dos esforços, a massa específica sendo reduzida em relação ao concreto convencional, facilita o transporte e o lançamento do concreto nas construções. Com isso pode-se dizer que trará uma maior feracidade no canteiro de obras.

\section{Conclusão}

A partir dos resultados obtidos e analisados, pode-se concluir que a adição de argila expandida e EPS pode diminuir a resistência das estruturas, porém

Gráfico 1. Massa específica.

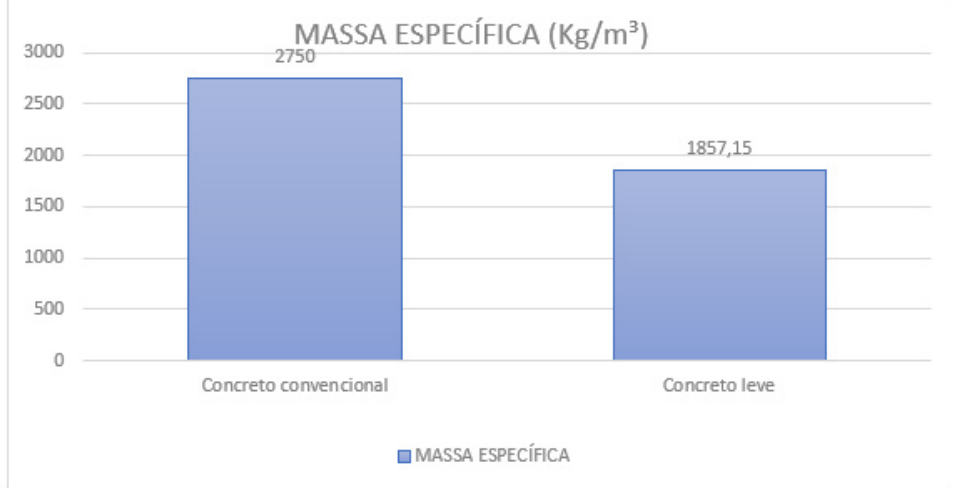

Fonte: Os autores 
Gráfico 2. Ensaio de compressão axial.

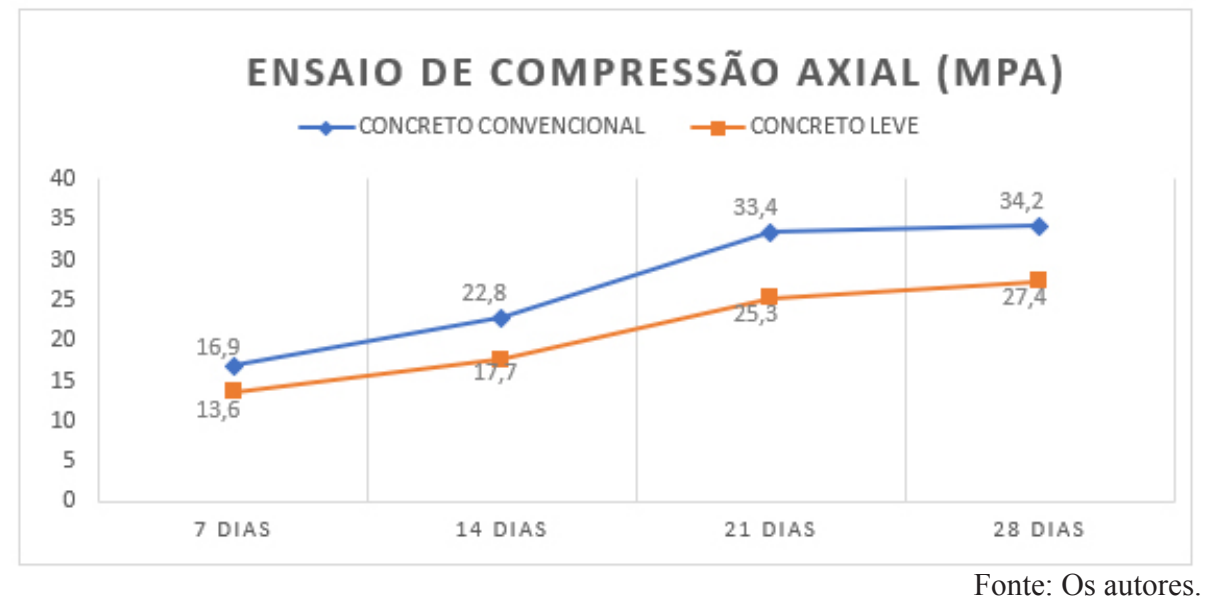

Gráfico 3. Fator de eficiência.

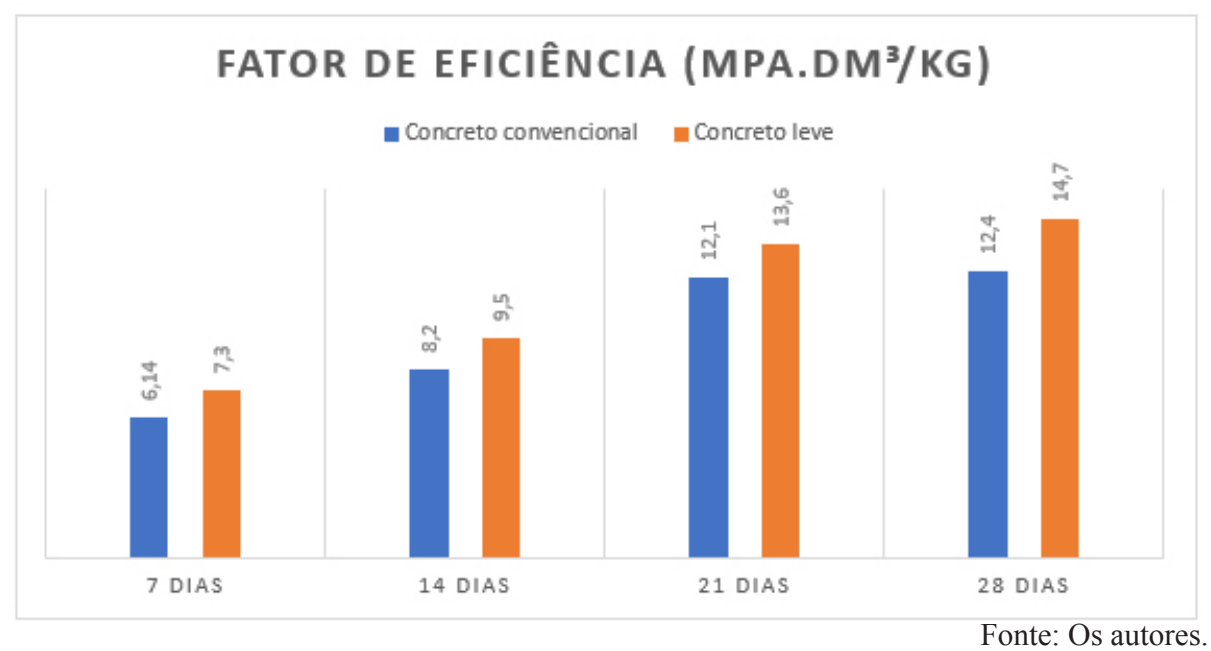

quando utilizados com esforços solicitantes obedecendo sua resistência à compressão se torna mais eficiente que o concreto convencional. Ou seja, o concreto leve possui uma resistência menor à compressão em relação ao concreto convencional. Contudo, este projeto experimental propiciou resultados onde através dos mesmos possibilita-se a utilização do concreto leve com função estrutural, pois sua resistência a compressão foi superior a $20 \mathrm{Mpa}$, valor mínimo para função estrutural de acordo com a NBR 6118:2041. Com isso o concreto leve torna-se benéfico para sua utilização na construção civil, já que apresenta uma redução significativa na sua massa específica, diminuindo significativamente o peso próprio de estruturas de concreto armado, pois minimiza os esforços solicitantes neste tipo de estruturas. Este tipo de concreto quando utilizado em obras civis ocasiona melhorias no custo total de construções, pois reduz o custo integral da obra.

Cabe ressaltar que para melhoria, trabalhos futuros a redução do diâmetro do agregado graúdo e a variação do mesmo para um possível aumento da resistência mecânica consequentemente aumentando o fator de eficiência.

\section{Referências Bibliográficas}

Associação Brasileira de Normas Técnicas. NBR 5738: Concreto Procedimento para moldagem e cura de corpos de prova. , revisada em 2018. Rio de Janeiro.

Associação Brasileira de Normas Técnicas. NBR 5739: Ensaio de compressão de corpo-de prova cilíndrica, revisada em 2018. Rio de Janeiro.

Associação Brasileira de Normas Técnicas. NBR 6118: Projeto de execução de obras de concreto armado, revisada em 2014. São Paulo

Associação Brasileira de Normas Técnicas. NBR 9833: Concreto fresco - Determinação da massa específica, do rendimento e do teor de ar pelo método gravimétrico, revisada em 2009. Rio de Janeiro.

Caldas-Branco, A. A. (2016). Tabela de Traços Eng. Caldas Branco, 1974.

Her-Yung, W. (2009). Durability of self-consolidating lightweight aggregate concrete using dredged silt. In: Construction and building materials, n. 23, p. $2332-2337$. 
Holm, T. A. (2000). Specified density concrete - A transition In: INTERNATIONAL SYMPOSIUM ON STRUCTURAL LIGHTWEIGHT AGGREGATE CONCRETE, 2. Krisitiansand, Norway, Proceedings, p.3746.

Moravia, W. G.; Oliveira, C. A. S.; Vasconcelos, W. L.; Gumieri, A. G. (2004), caracterização microestrutural de argila expandida para Aplicação como agregado em concreto estrutural leve Proceedings of the 48th Annual Meeting of the Brazilian Ceramic Society.

Pedroso, F. L. (2009). Concreto: as origens e a evolução do material construtivo mais usado pelo homem. Concreto e Construções, São Paulo, v. 53, n. 27, p.14-19, jan. 2009. Trimestral.

Spitzner, J. Higth-Strength L. W. A. (1994). Concrete In: Higth-Strength Concrete. RILEM, Cap. II - Aggregates. 